\title{
Notch dimerization is required for leukemogenesis and T-cell development
}

\author{
Hudan Liu, 1,2,3,8 Anthony W.S. Chi, ${ }^{3,8}$ Kelly L. Arnett, ${ }^{4,5}$ Mark Y. Chiang, ${ }^{1,6}$ Lanwei Xu, ${ }^{1,2,3}$ \\ Olga Shestova, ${ }^{1,2,3}$ Hongfang Wang, ${ }^{4}$ Yue-Ming Li, ${ }^{7}$ Avinash Bhandoola, ${ }^{3}$ 'Jon C. Aster, ${ }^{4}$ \\ Stephen C. Blacklow, ${ }^{4,5}$ and Warren S. Pear ${ }^{1,2,3,9}$ \\ ${ }^{1}$ Abramson Family Cancer Research Institute, University of Pennsylvania, Philadelphia, Pennsylvania 19104, USA; ${ }^{2}$ Institute for \\ Medicine and Engineering, University of Pennsylvania, Philadelphia, Pennsylvania 19104, USA; ${ }^{3}$ Department of Pathology and \\ Laboratory Medicine, University of Pennsylvania, Philadelphia, Pennsylvania 19104, USA; ${ }^{4}$ Department of Pathology, Brigham \\ and Women's Hospital, Harvard Medical School, Boston, Massachusetts 02115, USA; ${ }^{5}$ Dana-Farber Cancer Institute, Boston, \\ Massachusetts 02115, USA; ${ }^{6}$ Division of Hematology-Oncology, University of Pennsylvania, Philadelphia, Pennsylvania 19104, \\ USA; ${ }^{7}$ Molecular Pharmacology and Chemistry Program, Memorial Sloan-Kettering Cancer Center, New York, New York \\ 10065 , USA
}

Notch signaling regulates myriad cellular functions by activating transcription, yet how Notch selectively activates different transcriptional targets is poorly understood. The core Notch transcriptional activation complex can bind DNA as a monomer, but it can also dimerize on DNA-binding sites that are properly oriented and spaced. However, the significance of Notch dimerization is unknown. Here, we show that dimeric Notch transcriptional complexes are required for T-cell maturation and leukemic transformation but are dispensable for T-cell fate specification from a multipotential precursor. The varying requirements for Notch dimerization result from the differential sensitivity of specific Notch target genes. In particular, $c-M y c$ and pre-T-cell antigen receptor $\alpha$ (Ptcra) are dimerization-dependent targets, whereas Hey1 and CD25 are not. These findings identify functionally important differences in the responsiveness among Notch target genes attributable to the formation of higherorder complexes. Consequently, it may be possible to develop a new class of Notch inhibitors that selectively block outcomes that depend on Notch dimerization (e.g., leukemogenesis).

[Keywords: Notch; transcription; c-Myc; lymphocyte; T-ALL; leukemia]

Supplemental material is available at http://www.genesdev.org.

Received July 27, 2010; revised version accepted September 13, 2010.

Notch signaling regulates cell fate decisions, proliferation, survival, and metabolic activity in metazoan organisms (Artavanis-Tsakonas et al. 1999; Kopan and Ilagan 2009). The Notch pathway transduces intercellular signals that are initiated by binding of Notch ligands on signalsending cells with Notch receptors on signal-receiving cells. This event triggers a series of proteolytic cleavages that release intracellular Notch (ICN) from the plasma membrane, permitting ICN to enter the nucleus and form a Notch transcription complex with the transcription factor CSL (also known as RBP-J) and the coactivator Mastermind (MAML) (Kopan and Ilagan 2009).

The diverse outcomes of Notch signaling depend on Notch dose, context, and timing, yet how these variables impact Notch transcriptional activation are poorly understood (Bray 2006). One potential mechanism involves

${ }_{9}^{8}$ These authors contributed equally to this work.

${ }^{9}$ Corresponding author.

E-MAIL wpear@mail.med.upenn.edu; FAX (215) 573-6725.

Article published online ahead of print. Article and publication date are online at http://www.genesdev.org/cgi/doi/10.1101/gad.1975210. different configurations of CSL-binding sites in the promoters and/or enhancers of target genes. DNA containing one CSL-binding site can be loaded with a single CSL/ ICN/MAML complex (Nam et al. 2003, 2006; Wilson and Kovall 2006). Monomeric CSL/ICN/MAML complexes may produce different outcomes based on the number and location of dispersed CSL-binding sites in a given promoter. Alternatively, certain configurations of CSLbinding sites promote the formation of higher-order CSL/ ICN/MAML complexes. Bailey and Posakony (1995) identified conserved CSL-binding sites in the Drosophila enhancer of split locus that were oriented head to head and separated by 15-22 base pairs (bp) (so-called sequence paired sited [SPS]). In both the Drosophila enhancer of split locus and the promoter of mammalian Hes1, an enhancer of split homolog, the head-to-head orientation of the paired sites is critical for Notch-mediated transcriptional activation (Cave et al. 2005; Ong et al. 2006). The molecular logic underlying the orientation and spacing of paired sites was revealed by biochemical studies investigating the loading of complexes onto the Hes1 paired site, which showed that CSL/ICN/MAML 
complexes bind this site cooperatively, relying on intermolecular contacts involving amino acid residues located in the ICN ankyrin repeats (Nam et al. 2007). Cooperative binding requires the $\mathrm{N}$-terminal end of a MAML coactivator, which stabilizes the association of the Notch ankyrin repeat domain and CSL, and several intermolecular contacts between the Notch ankyrin repeats. One particularly important ankyrin repeat contact involves the residue R1985, which interacts with three backbone carbonyl groups in the ankyrin repeat domain of the adjacent ICN molecule (Nam et al. 2007). The ICN1 mutation R1985A prevents the formation of CSL/ICN/ MAML dimers on oligonucleotides containing paired sites and abolishes the ability of ICN1 to induce transcription from reporter genes under the control of promoters containing paired sites, yet ICN1-R1985A is fully competent to induce transcription from promoters containing polymeric head-to-tail CSL-binding sites (Nam et al. 2007). These data suggest that dimerization is likely to be required for activation of a subset of Notch target genes, but neither the identity of dimerization-dependent genes nor the circumstances in which they function have been studied.

T-cell development and transformation are excellent model systems in which to study mammalian Notch signaling, as Notch 1 is required at multiple stages of early T-cell development and dysregulated Notch1 signaling causes T-cell acute lymphoblastic leukemia (T-ALL) in both mice and humans (Radtke et al. 2010). Notch1 is required to generate the earliest T-cell progenitors (ETP) from multipotent lymphoid progenitors (MPP) in the thymus via signaling from the Notch ligand DLL4 (Sambandam et al. 2005; Tan et al. 2005; Hozumi et al. 2008; Koch et al. 2008). Inactivation of Notch1 signaling in hematopoietic stem cells (HSCs) or bone marrow (BM) MPPs results in the generation of intrathymic B cells and prevents T-cell development (Radtke et al. 1999; Wilson et al. 2001). Conversely, constitutive Notch signaling in HSCs and MPPs inhibits B-cell development and promotes thymic-independent T-cell development (Pui et al. 1999; De Smedt et al. 2002; Schmitt and Zuniga-Pflucker 2002; Hozumi et al. 2003). Subsequent to generating the earliest thymic progenitors, Notch1 signals provide essential differentiation, proliferation, survival, and metabolic signals during the early stages of T-cell development, up to and including $\beta$ selection, which is an important checkpoint where immature $T$ cells express pre-T-cell receptors (pre-TCRs) consisting of a pT $\alpha$ (pre-T-cell antigen receptor $\alpha$, Ptcra) chain and a TCR $\beta$ chain (von Boehmer and Fehling 1997; Michie and Zuniga-Pflucker 2002; Radtke et al. 2010). Following successful $\beta$ selection, T cells proliferate and differentiate into $\mathrm{CD} 4^{+} \mathrm{CD} 8^{+}$double-positive (DP) T cells. The essential requirement for Notch1 ends with successful $\beta$ selection (Wolfer et al. 2002; Tanigaki et al. 2004; Maillard et al. 2006; Radtke et al. 2010). The transcriptional targets of Notch1 that direct T-cell fate specification and/or subsequent steps of T-cell development include Hes1 (Tomita et al. 1999; Kaneta et al. 2000), IL7R (Gonzalez-Garcia et al. 2009), pT $\alpha$ (Deftos et al. 2000; Reizis and Leder 2002), and $c-M y c$ (Palomero et al. 2006; Sharma et al. 2006; Weng et al. 2006); however, the mechanism by which Notch regulates each target to orchestrate T-cell specification and differentiation is unknown.

Notch1 is an oncogene in human and murine T-ALL. In humans, Notch1 gain-of-function mutations occur in $>60 \%$ of patients with T-ALL, where they lead to ligand-independent Notch1 signaling and/or prolonged signaling (Aster et al. 2008). Dysregulated Notch1 signaling in murine T-ALL models leads to similar consequences (Aster et al. 2008). $c-M y c$ is a direct transcriptional target of Notch1 that has important functions in the initiation and maintenance of Notch-dependent T-ALL (Palomero et al. 2006; Sharma et al. 2006; Weng et al. 2006; Li et al. 2008). c-Myc can maintain the growth of Notch-dependent T-ALL cell lines in the absence of Notch, and c-Myc inhibition blocks T-ALL growth (Weng et al. 2006). Thus, inhibiting the Notch1:c-Myc axis may have therapeutic value in treating T-ALL.

In this study, we used T-cell development and transformation to characterize the dependence of these processes on the formation of dimeric Notch transcription complexes. We found that the formation of dimeric complexes is not required to specify the T-cell fate from a MPP; however, dimeric complexes have important functions in later stages of T-cell development and are required for T-cell transformation. Analysis of these varying requirements indicates that specific Notch target genes exhibit a differential dependence on dimerization. In particular, both $c-M y c$ and $p T \alpha$ require formation of dimeric Notch transcription complexes, whereas Hey1 and CD25 are dimerization-independent. Analysis of the paired binding sites in the human and murine $p T \alpha$ loci show that there is tolerance for deviation from the CSLbinding consensus at one of the two sites, suggesting that loading at a high-affinity site enables cooperative interaction of CSL with DNA at a second lower-affinity site. Transcription of both $c-M y c$ and $p T \alpha$ in response to activated Notch 1 relies on dimer formation, because mutations that inhibit homodimerization but reconstitute dimeric complexes in trans rescue expression of these targets and restore the growth of Notch-dependent T-ALL cell lines. These data show that a subset of Notch1 targets depends on formation of Notch1 dimeric transcription complexes, and that expression of these targets is important for both T-cell development and transformation.

\section{Results}

Dimeric Notch signaling is required for T-ALL but is dispensable for T-cell specification

Notch1 is required for the differentiation of hematopoietic precursors into T cells (Bhandoola et al. 2007; Radtke et al. 2010). In the absence of Notch1 signals, T cells do not develop (Radtke et al. 1999). In contrast, constitutive Notch1 signaling in MPPs induces thymic-independent T-cell development in the BM (Pui et al. 1999). To determine the effect of dimerization on T-cell specification, we transduced constitutively active ICN1 or dimerization-defective 
ICN1-R1985A (R1985A) into BM progenitors and cocultured these cells with OP9 cells, which give rise to myeloid cells or B cells in the absence of Notch signaling. In these experiments, we used total MPPs (defined as $\mathrm{Lin}^{-} \mathrm{Scal}^{+} \mathrm{Kit}^{+} \mathrm{Flt}^{+}{ }^{+}$, a heterogeneous population containing some thymus homing progenitors (Bhandoola et al. 2007) that can be isolated in sufficient quantities. In the absence of Notch1 signals, myeloid development occurred, as demonstrated by coexpression of the myeloid markers Gr1 and Mac1 (Fig. 1A, top). In contrast, ICN1 expression inhibited myeloid differentiation and induced early stages of T-cell development, as shown by coexpression of the T-cell markers CD25 and Thy1.2 (Fig. 1A, middle). R1985A also prevented myeloid development, supported early stages of T-cell development (Fig. 1A, bottom), and appeared as potent as ICN1 in inducing T-cell development at all time points examined (days 3, 6, and 9) (Fig. 1B; data not shown). Furthermore, based on CFSE labeling, both ICN1 and R1985A-transduced MPPs underwent similar numbers of cell divisions as they differentiated (Fig. 1C).

In addition to inducing thymic-independent T-cell development, constitutive ICN1 expression in murine hematopoietic progenitors induces T-ALL (Pear et al. 1996; Aster et al. 2000). Lethally irradiated recipients of ICN1-transduced HSCs uniformly developed T-ALL within $100 \mathrm{~d}$ (Fig. 1D). In contrast, mice receiving R1985A remained leukemia-free (Fig. 1D). This difference is not likely to result from a failure of the R1985A-transduced cells to engraft, survive, or promote T-cell specification following BM transplantation (BMT), as the percentage of Thy $1.2^{+} \mathrm{CD} 25^{+} \mathrm{GFP}^{+}$cells was similar between the ICN1 and R1985A mice at $2 \mathrm{wk}$ following BMT (data not shown). However, similar to other nontransforming Notch alleles that we studied, the percentage of GFP-expressing cells in the R1985A mice decreased over time (data not shown), since these cells are unable to self-renew (Chiang et al. 2008). Thus, R1985A abrogated the ability of Notch1 to induce T-ALL without affecting T-cell specification.

\section{Dimeric Notch signaling is required to maintain growth of T-ALL cell lines}

To understand the failure of R1985A to induce T-ALL, we studied its effect on the growth of two Notch1-dependent murine T-ALL cell lines: G4A2 and T6E (Pear et al. 1996, 1998). Both express mutated gain-of-function alleles encoding Notch1 polypeptides that signal independently of ligand but still require $\gamma$-secretase-dependent cleavage to create ICN1 (Pear et al. 1996). Treating MigR1 vectortransduced G4A2 and T6E cells with the $\gamma$-secretase inhibitor (GSI) JC-18 (also known as GSI-X1) (Wu et al. 1998; Searfoss et al. 2003) blocked Notch signaling and inhibited growth of these cells (Fig. 2A,B; data not shown). Transducing these cells with ICN1, which does not require $\gamma$-secretase cleavage for activity, maintained their growth in the presence of the GSI (Fig. 2A,B). In contrast to ICN1, R1985A did not rescue GSI-induced
A.
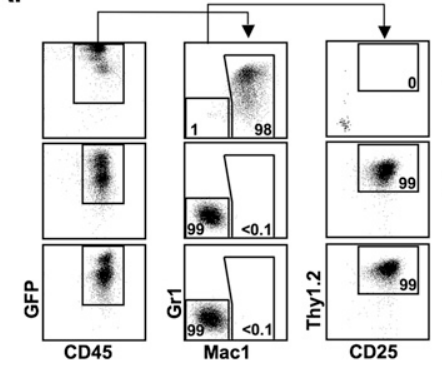

C.

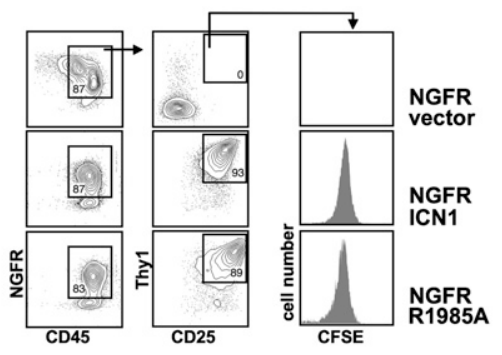

B.

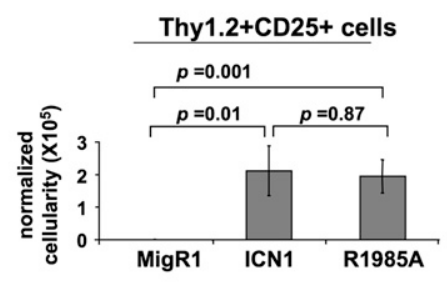

D.

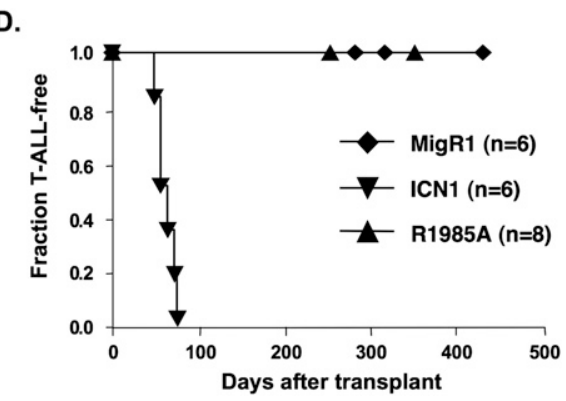

Figure 1. R1985A induced T-cell specification from a MPP but failed to induce T-ALL. (A) Hematopoietic MPPs were purified from C57BL/6 BM and transduced with retroviruses (MigR1) expressing GFP alone or GFP and the indicated polypeptides for $48 \mathrm{~h}$. Transduced cells were sorted by GFP expression and seeded at equal numbers (250 cells) onto OP9 stromal cells. Following $6 \mathrm{~d}$ of coculture with $\mathrm{OP} 9, \mathrm{GFP}^{+} \mathrm{CD} 45^{+}$ cells were gated to evaluate the myeloid lineage by detecting the surface markers Mac1 and Grl. Nonmyeloid cells $\left(\mathrm{Macl}^{-} \mathrm{Grl}^{-}\right)$ were examined further for T-lineage development by Thy1.2 and CD25 expression. Gated live cells $\left(\mathrm{DAPI}^{-}\right)$were analyzed and representative profiles are shown. (B) Relative numbers of Thy $1.2^{+} \mathrm{CD} 25^{+}$cells generated from retrovirally transduced MPPs cocultured on OP9 were quantified and averaged from three independent experiments. Bars denote standard error of mean (SEM). P-values were determined by Student's $t$-test. $(C)$ MPPs were transduced with retroviral vectors expressing the indicated cDNA and truncated nerve growth factor receptor (tNGFR) as a surrogate marker. Cells were labeled with CFSE and cultured on OP9 cells for $3 \mathrm{~d}$. CFSE expression was determined on the CD $45^{+} \mathrm{NGFR}^{+}$Thy $1.2^{+} \mathrm{CD} 25^{+}$population. $(D)$ Lethally irradiated mice were reconstituted with 5-FU-treated donor BM cells that were transduced with the MigR1 retroviral vector, ICN1, or R1985A. The Kaplan-Meier graph shows the fraction of mice without T-ALL as a function of time. MigR1 and ICN1 mice served as negative and positive controls, respectively. Peripheral blood from all mice was drawn 4 wk and 6 wk after BMT to follow T-ALL development. Only ICN1 mice were confirmed to develop T-ALL with an elevated white blood cell count (WBC $>40$ million cells per milliliter) containing $>90 \% \mathrm{GFP}^{+} \mathrm{CD} 4^{+} \mathrm{CD} 8^{+} \mathrm{DP}$ T cells. 


\section{A. G4A2}
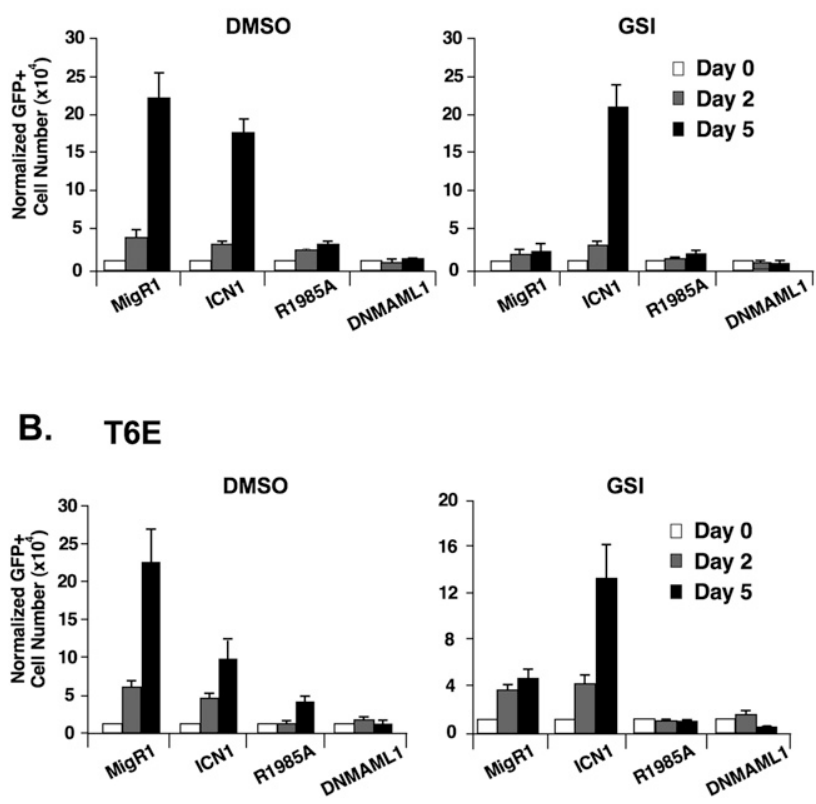

Figure 2. R1985A blocked Notch-dependent cell growth. G4A2 $(A)$ or T6E $(B)$ cells express a membrane-tethered mutated form of Notch1 that requires $\gamma$-secretase-dependent cleavage for activity. The cells were transduced with MigR1 retroviruses expressing GFP alone (MigR1) or GFP and the indicated polypeptides for $48 \mathrm{~h}$, followed by treatment with the GSI JC-18 $(1 \mu \mathrm{M})$ or vehicle (DMSO) for $5 \mathrm{~d}$. $\mathrm{GFP}^{+}$cell numbers, determined at each time point using a Vi-CELL Cell Viability Analyzer (Beckman Coulter) and FACS, are shown as the mean of values from triplicate wells \pm SD. Cell numbers from $2 \mathrm{~d}$ and $5 \mathrm{~d}$ were normalized to $0 \mathrm{~d}$. Data are representative of three independent experiments.

growth inhibition in either T6E or G4A2 cells (Fig. 2A,B). The growth inhibitory effect of R1985A is not likely to result from differences in protein levels, as the steadystate levels of ICN1 and R1985A were similar (data not shown). Furthermore, R1985A inhibited the proliferation of both cell lines in the vehicle (DMSO) treatment, suggesting that R1985A exerts some dominant-negative activity that suppresses Notch-dependent genes required for growth of these cells (Fig. 2A,B).

Dimeric Notch complexes regulate a subset of Notch transcriptional targets that include c-Myc and $\mathrm{pT} \alpha$

The inability of R1985A to support the growth of the Notch-dependent T-ALL lines or induce T-ALL in mice suggested that R1985A failed to induce the expression of one or more critical target genes that are essential for leukemogenesis. We thus tested whether R1985A would support the expression of a subset of Notch target genes identified previously in T6E cells (Weng et al. 2006). Fifteen hours following transduction with ICN1, R1985A, dominant-negative MAML1 (DNMAML1), or empty virus, T6E cells were treated with JC-18 for $6 \mathrm{~h}$. Cell numbers were equivalent at the time of harvest. Quantitative PCR (qPCR) analysis of RNAs purified from $\mathrm{GFP}^{+}$cells (a surrogate marker for retroviral transduction) revealed three types of responses among various Notch target genes (Fig. 3). (1) R1985A and ICN1 rescued Hey1 and $C D 25$ to a similar extent in the presence of the GSI (Fig. 3A,B). (2) R1985A failed to further increase the expression of Hes1 relative to the vector control in the presence of DMSO; however, in the presence of the GSI, Hes1 expression was increased relative to MigR1 or DNMAML1transduced cells, albeit to a lesser degree than by ICN1 (Fig. 3C). The ability of R1985A to partially rescue the expression of Hes1 was unexpected, as R1985A had minimal activity on a luciferase reporter gene containing only the Hes1 paired site (Nam et al. 2007). These data raise the possibility that additional CSL-binding sites in the proximal Hes1 promoter also contribute to the regulation of Hes1 in T-ALL cells. (3) R1985A failed to induce $c-M y c$ or $p T \alpha$ expression in the presence and absence of the GSI (Fig. $3 \mathrm{D}, \mathrm{E})$.

$\mathrm{pT} \alpha$ contains paired binding sites that respond to dimeric Notch signaling

$\mathrm{pT} \alpha$ is an important component of the pre-TCR that is required for successful $\beta$ selection and differentiation to the $\mathrm{CD} 4^{+} \mathrm{CD} 8^{+} \mathrm{DP}$ stage of T-cell development. $p T \alpha$ is a direct Notch1 transcriptional target (Deftos et al. 2000), and CSL-binding sites have been identified in both human and mouse enhancer sequences (Reizis and Leder 2002). Because R1985A blocked Notch1-induced $p T \alpha$ expression, we reasoned that expression of $p T \alpha$ was dependent on the formation of dimeric Notch transcription complexes. Although inspection of the previously identified CSL-binding sites in the proximal $p T \alpha$ enhancer in mice and humans did not reveal an ideal match to the CSLbinding consensus at the typical position of the second site (i.e., positioned head to head and separated by a distance of 15-17 bp from the primary site, as exists in the Hes1 promoter) (Nam et al. 2007), we explored the possibility that cooperative loading of dimeric complexes would be tolerant of divergence from the consensus at the second site (Fig. 4A).

To determine whether a Notch transcriptional complex comprised of CSL, ICN1, and MAML1 can cooperatively dimerize on the putative $p T \alpha$ paired site, we carried out electrophoretic mobility shift assays (EMSAs) on oligonucleotide probes containing the $p T \alpha$ SPS (Fig. 4B). In the absence of ICN1 or MAML1, CSL preferentially bound to a single site. Adding ICN1 or R1985A shifted this single complex equivalently, consistent with prior work showing that the R1985A mutation has no effect on ICN1 association with CSL. In contrast, the addition of the MAML1 peptide induced the formation of a higher-order CSL/ICN1/MAML1 complex with wild-type ICN1 on both the human and murine $p T \alpha$ elements, whereas the R1985A mutation was completely unable to form stable higher-order CSL/ICN1/MAML1 complexes (Fig. 4B). To assess the ability of CSL to bind each individual site, oligonucleotide probes were prepared that contained either a mutant high-affinity site (Site 1) or a mutant low-affinity site (Site 2). CSL bound to the high-affinity site but not the 
A.

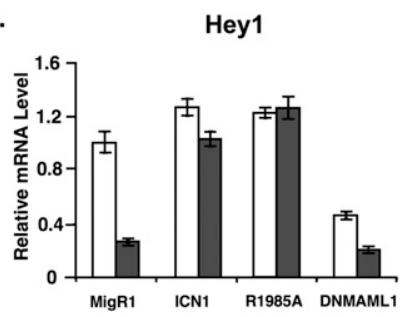

B.

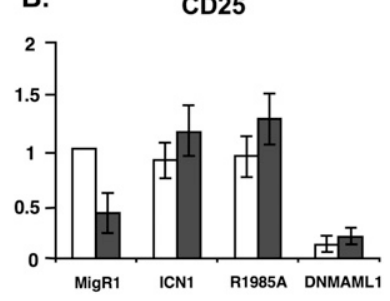

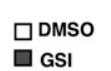

$\square$ GSI

Figure 3. R1985A differentially influences Notch target gene expression. To measure the mRNA levels of direct Notch transcriptional targets, T6E cells were transduced with the indicated retroviruses for $15 \mathrm{~h}$ followed by $6 \mathrm{~h}$ of GSI treatment. The GFP ${ }^{+}$ population was sorted, followed by total RNA isolation and reverse transcription. Hey1 $(A), C D 25(B)$, Hes1 $(C), c-M y c(D)$, and $p T \alpha(E)$ transcript levels were measured by qPCR. The expression of each gene relative to 18s RNA is shown as the mean of values from triplicate wells \pm SD. Representative data from three independent experiments are shown. The primers are described in the Materials and Methods.
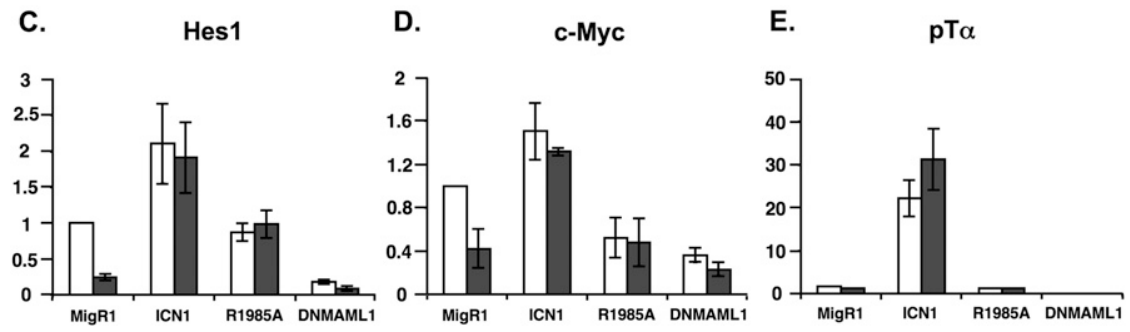

low-affinity site (Supplemental Fig. S1). Thus, the binding of a single Notch transcriptional complex onto a highaffinity CSL site in the $p T \alpha$ promoters of humans and mice allows subsequent MAML- and R1985-dependent cooperative loading of complexes onto a second flanking site that differs from the CSL-binding site consensus.

To directly test whether loading of Notch transcription complex dimers is required for activation of the $p T \alpha$ enhancer, we used human $p T \alpha$ reporter genes (Fig. 4C; Reizis and Leder 2002). ICN1 strongly activated a wildtype $p T \alpha$ reporter gene, but failed to activate when the high-affinity CSL-binding site (CCTGGGAA) was mutated. In contrast, activation of the wild-type $p T \alpha$ reporter gene by R1985A was markedly diminished. The degree of the decrement in activation produced by the R1985A mutation on the $p T \alpha$ reporter gene was similar to that seen with a Hes1 reporter gene containing a well-characterized paired site (Fig. 4C; Nam et al. 2007).

To establish that the defect in the R1985A mutant resulted from defective Notch dimerization, we scored additional ICN1 mutations affecting other contacts involved in the formation of dimeric CSL/ICN1/MAML1 complexes on DNA (Fig. 4D; Nam et al. 2007). Specifically, CSL/ICN1/MAML1 dimers contain an intermolecular salt bridge between K1946 and E1950 of ankyrin repeat 2 (Fig. 4D). In prior work, we showed that charge reversal mutations (either K1946E or E1950K) that disrupt this salt bridge decreased the ability of ICN1 to activate a reporter gene containing the Hes1 paired site. In contrast, combining both charge reversal mutations (K1946E/E1950K) in cis, which restores electrostatic complementarity, also restored activation of the Hes1 reporter gene, providing strong evidence that Notch dimerization is critical for transcriptional activation (Nam et al. 2007).

We used the same strategy to test the role of dimerization in activation of the human $p T \alpha$ reporter gene (Fig. 4E). Both of the individual K1946E and E1950K mutations diminished $p T \alpha$ reporter gene activation by ICN1 to a degree similar to that seen on the Hes1 reporter gene
(Nam et al. 2007). In contrast, the charge reversal mutation K1946E/E1950K not only restored activation, but reproducibly caused increased transcription of the $p T \alpha$ reporter gene as compared with wild-type ICN1. The explanation for the increased activity of the double mutant is unclear, but the observed structure-based complementation nevertheless provides strong evidence that the formation of dimeric Notch transcription complexes on the $p T \alpha$ enhancer is required for transcriptional activation.

\section{Dimeric Notch complexes are important for $\beta$ selection}

$\beta$ selection is a critical juncture of T-cell development during which cells express a functional pre-TCR $\beta$ receptor and initiate signals that result in the survival and expansion of these cells (von Boehmer and Fehling 1997; Aifantis et al. 2006). Cells undergoing $\beta$ selection are irreversibly committed to the T-cell lineage. Notch1 and $c-M y c$ are highly expressed in cells just prior to $\beta$ selection (so-called DN3a cells) and are down-regulated in cells immediately post- $\beta$ selection (so-called DN3b cells) (Taghon et al. 2006; Weng et al. 2006; Yashiro-Ohtani et al. 2009). Notch withdrawal in DN3a cells decreased $c-M y c$ to levels typical of DN3b cells, suggesting that Notch1 regulates $c-M y c$ expression at this developmental stage (Weng et al. 2006). However, the precise roles of Notch 1 and c-Myc during $\beta$ selection have not been clearly delineated. The inability of R1985A to induce $c-M y c$ expression provides a unique reagent to investigate these relationships. First, to confirm that R1985A did not lead to increased expression of $c-M y c$ in DN3 cells, ICN1 or R1985A transduced DN3 cells were cultured on OP9 cells for $2 \mathrm{~d}$ prior to RNA harvest. Similar to the data in leukemic cell lines, R1985A induced transcription of Hey1 but not $c-M y c$ (Fig. 5A).

To test the ability of R1985A to induce successful passage of T-cell precursors through $\beta$ selection, we used OP9 culture conditions that support the differentiation of DN3 cells to DP cells in the presence of Notch1 
Liu et al.

A.

\section{Murine pTa}

GCAGG CCTGGGA CACGTGGAGCCCACAG TACCCAAA GCCCCTCCCGC CGTCCC GGACCCTI GTGCACCTCGGGTGTC ATGGGTTT CGGGGAGGCG

\section{Human pTa}

GCTGTG CCTGGGA CGCGCGGGACCGCG CCTCCAG CAGCCCTGCGC CGACAC GGACCCTI GCGCGCCCCTGGCGCC GGAGGTCC GTCGGGACGCG

C.

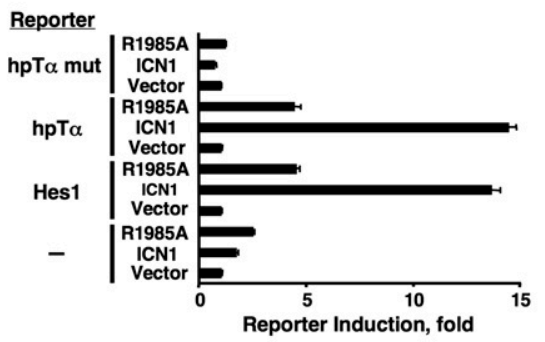

E.

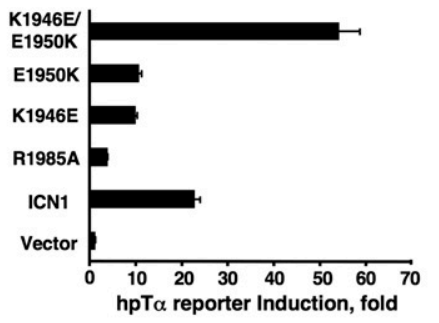

B.

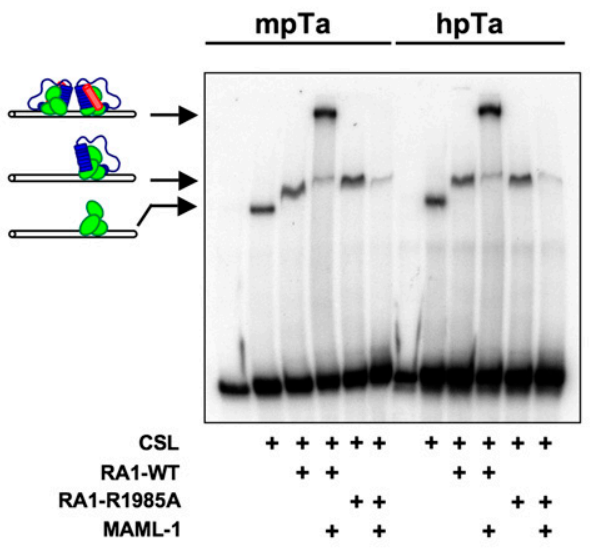

D.

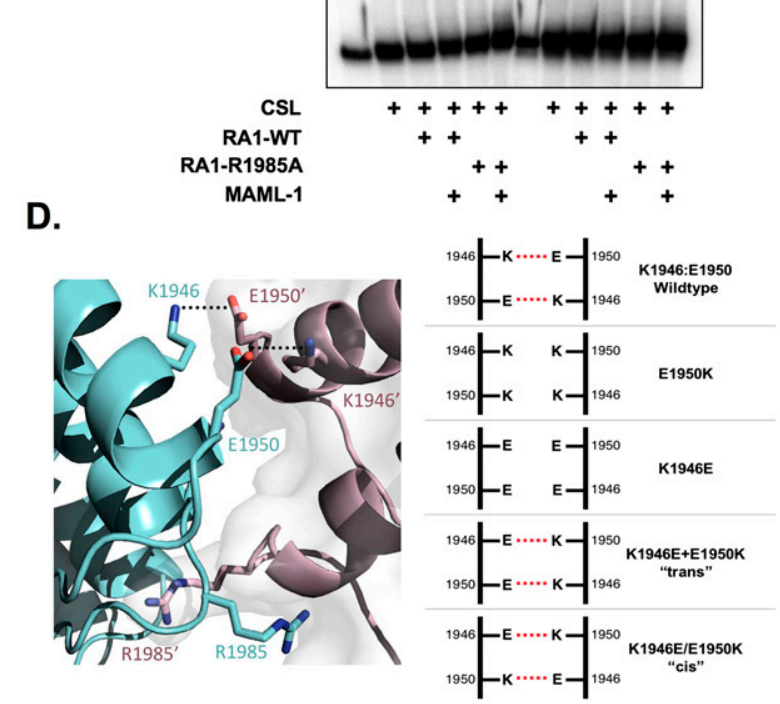

Figure 4. Dimeric Notch1 directly regulates $p T \alpha$ transcription. (A) Schematic of the reported CSL-binding sites in both human and mouse $p T \alpha$ enhancers (left box in red) (Reizis and Leder 2002) and predicted cryptic second SPS sites (right box in blue). (B) Dimeric ICN1 transcriptional complex assembled in the presence of $p T \alpha$ enhancer. EMSA was performed with radiolabeled oligonucleotide probes, and the resulting complexes constituted with recombinant proteins are indicated. RA1 denotes the RAMANK domain of human ICN1. (C) Wild-type ICN1 but not R1985A fully induced human $p T \alpha$ enhancer. 293 cells were transiently transfected with the reporter constructs together with the ICN1 or R1985A expression vectors. The luciferase reporter constructs contained the indicated enhancer fragments upstream of the SV40 promoter TATA box. The human $p T \alpha$ enhancers were either wild type or mutated at the CSL-binding sites as described (Reizis and Leder 2002). Reporter activities normalized to an empty vector were determined and presented as fold induction, shown as the mean of values from triplicate wells \pm SD. Data are representative of three independent experiments. $(D)$ Key interactions between symmetry mates in the structure of the Notch transcription complex (Protein Data Bank ID code 2F8X). One of the symmetry-related Notch ankyrin domains is colored blue, and the other is pink. Residues that form contacts between symmetry mates are labeled. The pink copy also has a transparent molecular surface. Dotted lines denote salt bridges between K1946 and E1950' and E1950 and K1946'. The different K1946 and E1950 mutants used to analyze Notch dimerization are shown on the right. Predicted salt bridges are indicated by the dashed red lines. $(E)$ Induction of the human $p$ T $\alpha$ enhancer by both wild-type ICN1 and a variant containing dual mutations (K1946E/E1950K). Similar to the transfections in $C$, the luciferase reporter construct containing the human $p T \alpha$ enhancer upstream of the SV40 promoter TATA box was coexpressed with the indicated ICN1 and mutants. Reporter activities were determined and normalized to the empty vector as induction fold, shown as the mean of values from triplicate wells \pm SD. Data are representative of three independent experiments.

signaling. We purified C57BL/6 DN3 thymocytes, which were subsequently transduced with different combinations of retroviruses expressing ICN1, R1985A, or c-Myc. The transduced DN3 cells were sorted and 200 cells were cultured for $9 \mathrm{~d}$ with OP9 cells, at which time DP T-cell development was assessed (Supplemental Fig. S2).

DN3 cells transduced with empty retroviral vectors did not survive, consistent with previous reports showing that Notch is required for DN3 survival (Fig. 5B, row 1, Ciofani et al. 2004). As expected, transduction with either ICN1 or ICN1 and c-Myc together generated DP T cells (Fig. 5B, rows 2,5). Viable cells were present following
DN3 transduction with either R1985A or c-Myc; however, DP T cells were rare (Fig. $5 \mathrm{~B}$, rows 3,4 ). In contrast, when R1985A and c-Myc were coexpressed, they did induce DP T-cell development (Fig. 5B, row 6), suggesting that c-Myc complemented R1985A to promote successful $\beta$ selection and DP T-cell development. Coexpression of R1985A and c-Myc consistently resulted in fewer total DP T cells than the combination of ICN1 and c-Myc (Fig. 5C). This may be due to subnormal expression of other Notch1 target genes in cells expressing R1985A, such as Hes1 or $p T \alpha$. Unlike c-Myc, retroviral expression of $\mathrm{pT} \alpha$ failed to complement R1985A, as assessed by an inability 
A.
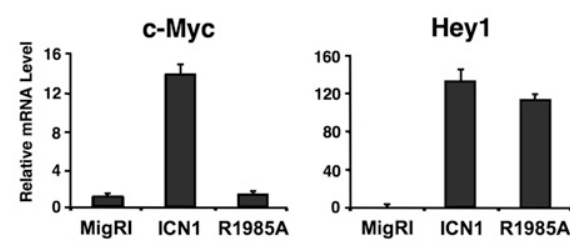

C.

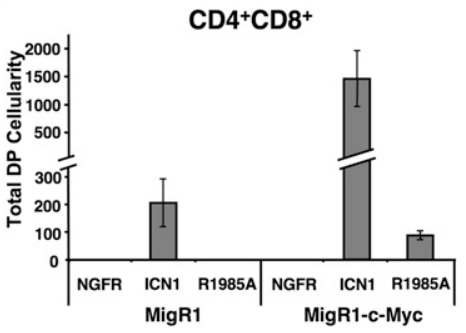

B.

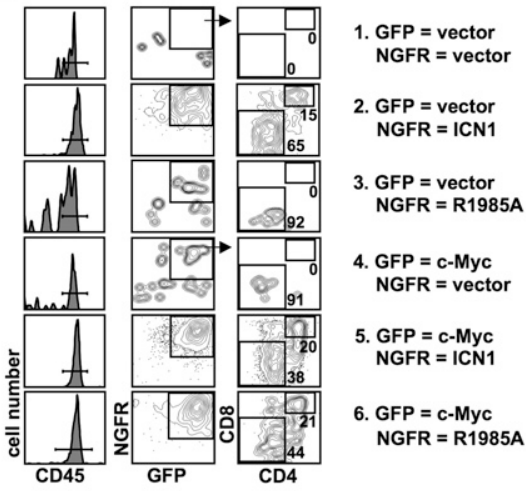

D.

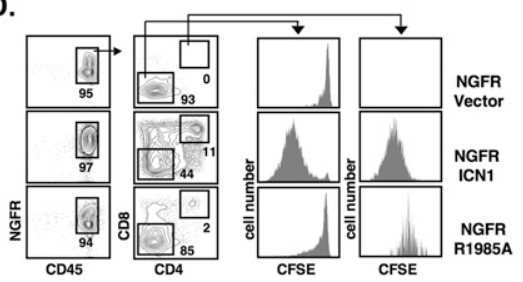

Figure 5. c-Myc overrides the R1985Ainduced block in DP T-cell development. (A) R1985A failed to activate $c-M y c$ expression in primary DN3 thymocytes. DN3 cells were sorted from the thymus of B6 mice and transduced with the indicated retroviral supernatants. At $16 \mathrm{~h}$ post-transduction, the transduced DN3 cells were purified and cocultured with OP9 cells for $2 \mathrm{~d}$, then RNA was obtained to analyze gene expression by qPCR. $c-M y c$ and Hey 1 expression relative to 18s RNA is shown as the mean of values from triplicate wells \pm SD. Data are representative of two independent experiments. (B) Purified DN3 cells were transduced with the indicated pairs of retroviruses and $200 \mathrm{NGFR}^{+} \mathrm{GFP}^{+}$cells were sorted and cultured with OP9 cells for $9 \mathrm{~d}$, whereupon the $\mathrm{CD} 45^{+}$cells were immunophenotyped for CD4 and CD8 expression. Thymocytes from a C57BL/6 mouse were analyzed as controls to gate $\mathrm{CD}^{+} \mathrm{CD}^{+}$and $\mathrm{CD}^{-} \mathrm{CD} 8^{-}$populations (data not shown). The percentage of cells in the bottom left and top right quadrants is shown. Representative profiles are shown. Gated live cells $\left(\mathrm{DAPI}^{-}\right)$were analyzed. Experiments were performed at least three times with similar results. $(C) \mathrm{CD}^{+} \mathrm{CD} 8^{+}$cells generated from retrovirally transduced DN3 cells in $B$ were quantified. The cell number in each condition is shown as the mean of values from triplicate wells \pm SD. Data are representative of three independent experiments. $(D) \mathrm{DN} 3$ cells were transduced with retroviral vectors expressing the indicated cDNA and tNGFR as a surrogate marker. Cells were labeled with CFSE and cultured on OP9 cells for $5 \mathrm{~d}$. CFSE levels were determined on the indicated CD45 ${ }^{+} \mathrm{NGFR}^{+} \mathrm{CD} 4{ }^{-} \mathrm{CD} 8^{-}$and $\mathrm{CD}_{4} 5^{+} \mathrm{NGFR}^{+} \mathrm{CD} 4^{+} \mathrm{CD} 8^{+}$populations.

to induce DP T-cell development or substitute for ICN1 in maintaining the growth of T6E or 8946 cells treated with GSI (data not shown).

To further characterize the effect of Notch dimerization on $\beta$ selection, we used CFSE labeling of transduced DN3 cells in OP9 cultures to assess cellular proliferation (Fig. 5D). Vector-transduced DN3 cells failed to proliferate and differentiate in OP9 cultures at day 5 , whereas the vast majority of both differentiated and undifferentiated ICN1-transduced cells had undergone multiple cell divisions. In contrast, very few of the $\mathrm{CD} 4^{-} \mathrm{CD} 8^{-} \mathrm{DN}$ cells transduced with R1985A divided, and those that did underwent fewer divisions than the ICN1-transduced cells. The rare DP T cells in the R1985A-transduced cultures at day 5 also underwent fewer divisions than their ICN1transduced counterparts. However, no R1985A-transduced DP cells could be recovered when the cultures were maintained beyond $9 \mathrm{~d}$ (Fig. 5B,C). Furthermore, the overall cellularity was markedly decreased in the R1985A-transduced DN3 cells on day 9 (ICN1: $750 \pm 66$, R1985A: $21 \pm$ 2 ). Together, these data suggest that dimeric Notch signaling exerts multiple important functions at $\beta$ selection that influence both the differentiation and numbers of DP T cells.

Notch-dependent c-Myc expression and leukemic cell growth require Notch1 dimerization

In addition to influencing $\beta$ selection, the Notch:c-Myc axis is essential for the growth and survival of multiple
Notch-dependent T-ALL cell lines, including G4A2 and T6E. Thus, the failure of R1985A to induce $c-M y c$ transcription explains the dominant-negative growth effects of R1985A on G4A2 and T6E (Fig. 2), as the growth of both of these cell lines requires c-Myc (Weng et al. 2006; Chiang et al. 2008; Yashiro-Ohtani et al. 2009). To further explore the possible link between the R1985A mutation, $c-M y c$, and T-ALL cell growth, we tested the ability of R1985A to rescue growth of 8946 cells, a line derived from a murine T-ALL induced with a doxycycline-repressible human $c-M Y C$ transgene (Felsher and Bishop 1999). 8946 cells are c-MYC-dependent and die in the presence of doxycyline due to repression of transgenic $c-M Y C$ expression (Weng et al. 2006). We showed previously that 8946 cells were resistant to doxycycline-induced death after ICN1 transduction, which maintained cell growth by inducing the expression of the endogenous murine $\mathrm{c}-\mathrm{Myc}$ gene (Weng et al. 2006). Consistent with its effect on c-Myc transcription in T6E cells, R1985A failed to maintain 8946 cell growth in the presence of doxycycline (Fig. 6A). In contrast, retroviral coexpression of c-Myc and R1985A permitted 8946 cells to grow in the presence of doxycycline (Fig. 6A), consistent with the idea that a central facet of the inability of R1985A to support T-ALL cell growth is the failure to upregulate $\mathrm{c}-\mathrm{Myc}$ expression.

To establish that Notch1-dependent $c-M y c$ transcription required Notch dimerization, we tested the effects of the R1985A, K1946E, and E1950K mutations on $c-M y c$ transcription in the c-Myc-dependent 8946 T-ALL cells. Both of the individual K1946E and E1950K mutations 
Liu et al.

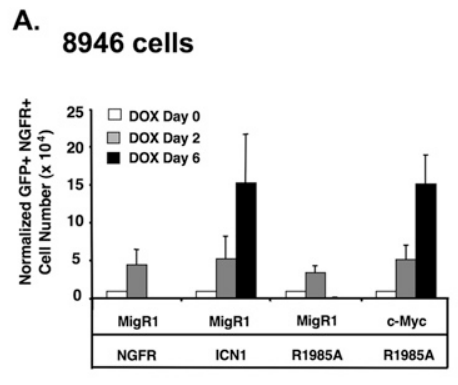

C.

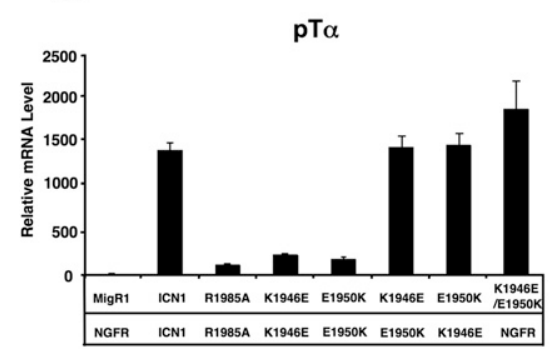

B.

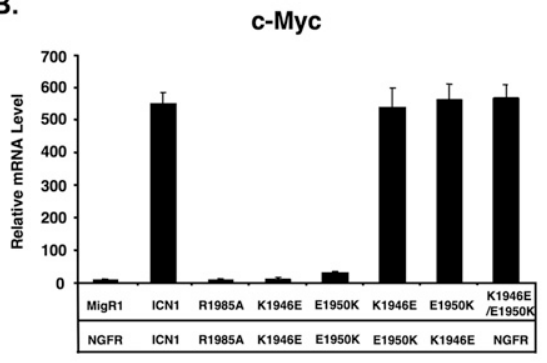

D.

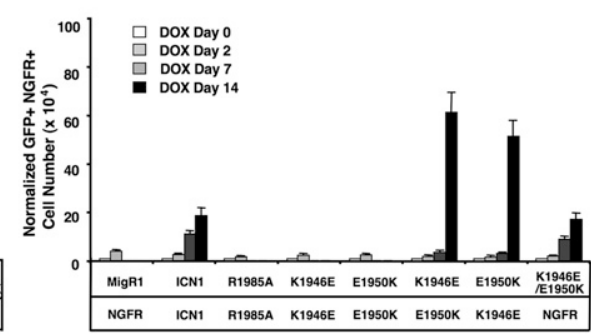

Figure 6. Notch dimerization regulates $c$ $M y c$ and $p T \alpha$ expression in vivo. (A) Exogenous c-Myc expression maintained growth of R1985A-expressing 8946 cells. 8946 cells were transduced with pairs of retroviruses that expressed either GFP or tNGFR as surrogate markers for $48 \mathrm{~h}$, followed by doxycycline $(20 \mathrm{ng} / \mathrm{mL})$ treatment for $6 \mathrm{~d}$. $\mathrm{GFP}^{+} \mathrm{NGFR}^{+}$cell numbers were determined at each time point and are shown as the mean of values from triplicate wells \pm SD. Cell numbers from $2 \mathrm{~d}$ and $6 \mathrm{~d}$ were normalized to that from $0 \mathrm{~d}$. Data are representative of three independent experiments. $(B, C) 8946$ cells were transduced with viruses expressing ICN1 or the indicated mutants for $24 \mathrm{~h}$, then treated with doxycycline $(20 \mathrm{ng} / \mathrm{mL})$ for an additional $24 \mathrm{~h}$. The sorted $\mathrm{GFP}^{+}$cells were harvested and RNA was obtained to analyze gene expression by qPCR. $c-M y c(B)$ and $p T \alpha(C)$ expression relative to 18s RNA are shown as the mean of values from triplicate wells \pm SD. Representative data from two independent experiments are shown. $(D)$ The remaining cells were maintained in doxycycline $(20 \mathrm{ng} / \mathrm{mL})$ treatment for up to $14 \mathrm{~d}$. GFP ${ }^{+} \mathrm{NGFR}^{+}$cell numbers, determined at the indicated times using a Vi-CELL Cell Viability Analyzer (Beckman Coulter) and FACS, are shown as the mean of values from triplicate wells \pm SD. Cell numbers from $2 \mathrm{~d}, 7 \mathrm{~d}$, and $14 \mathrm{~d}$ were normalized to $0 \mathrm{~d}$. Data are representative of two independent experiments.

diminished $c-M y c$ transcription by $>100$-fold, whereas the double mutant K1946E/E1950K restored $c-M y c$ expression to levels produced by wild-type ICN1 (Fig. 6B). To formally show that the double mutant K1946E/ E1950K functioned through intermolecular Notch1 interactions, we introduced the K1946E and E1950K mutants on separate retroviral vectors (Fig. 4D, "trans"). This combination also induced $c-M y c$ expression at wild-type ICN1 levels (Fig. 6B). Similar results were found for $p T \alpha$ in 8946 cells (Fig. 6C). Furthermore, while neither K1946E nor E1950K rescued 8946 cells from transgenic c-Myc withdrawal, both the K1946E/E1950K double mutant and the coexpressed K1946E and E1950K single mutants did (Fig. 6D). Together, these data provide strong ex vivo genetic evidence that dimerization-dependent Notch signaling is required in T cells for $c-M y c$ and $p T \alpha$ expression and growth of c-Myc-dependent T-ALL cells.

\section{Discussion}

Recent biochemical studies established that Notch has the capacity to dimerize at paired CSL sites that are optimally spaced and oriented (Nam et al. 2007); however, the functional significance of dimerization-dependent Notch signaling and the identity of physiologic dimer-dependent Notch targets were unknown. We now demonstrate that Notch1 dimerization regulates a subset of Notch1 functions by inducing a specific group of Notch1 transcriptional targets (Fig. 7). Using T-cell development and transformation as models, we show that Notch1 dimerization is essential to induce murine T-ALL and exerts important functions during T-cell $\beta$ selection, but is not required for induction of T-cell lineage specification. We identified two Notch1 transcriptional targets $(c-M y c$ and $p T \alpha)$ whose expression is dependent on Notch1 dimerization, as well as two targets (Hey1 and CD25) whose expression is independent of Notch1 dimerization.

\section{1) Notch activates as a monomer}

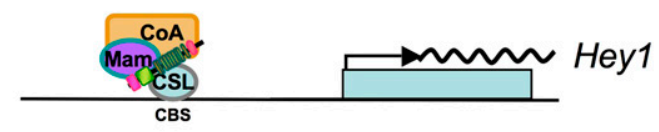

2) Notch activates as a dimer

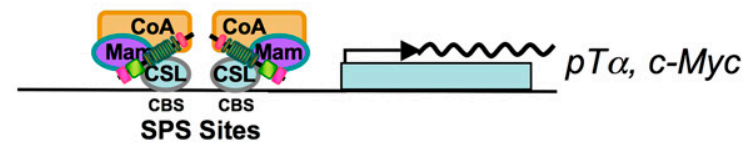

3) Monomeric and Dimeric Notch binding contribute

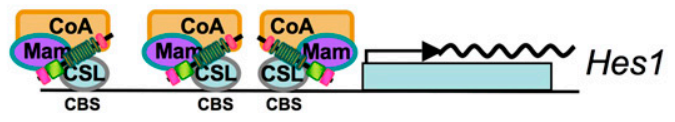

Figure 7. Models of dimerization-dependent or independent Notch transcription. (CBS) CSL-binding site. Notch1 transcriptional targets such as Hey1 do not require dimerization, whereas others, such as $c-M y c$ and $p T \alpha$, are dimerization-dependent. SPSs in $p T \alpha$ are shown to locate in its enhancer, constituted by a canonical CSL-binding site and a cryptic site 16 bp downstream apart. The location of the SPS sites in $c-M y c$ is not yet determined. Hes1 transcription is predicted to depend on Notch binding as both a monomer and dimer. 
Our analysis reveals important roles for dimeric Notch complexes in T-cell development and transformation. $c-M y c$ is a direct Notch1 transcriptional target in Notchdependent human and murine T-ALLs, in which the Notch:c-Myc axis exerts important growth and survival functions (Palomero et al. 2006; Sharma et al. 2006; Weng et al. 2006; Li et al. 2008). Disrupting Notch dimerization abrogated Notch-induced T-ALL in a murine BMT model and blocked the proliferation and survival of T-ALL cell lines. The failure of dimerization-deficient mutants to activate $c-M y c$ transcription is likely to be a critical event underlying these phenotypes, a contention supported by the ability of c-Myc to rescue growth and survival of T-ALL cell lines expressing dimerization-deficient mutants. The ability of Notch dimerization to influence specific events may be threshold-dependent, as the individual K1946E and E1950K mutants were less crippled than R1985A in terms of their abilities to induce $c-M y c$ expression, but still failed to rescue the growth of a c-Myc-dependent T-ALL cell line.

In contrast to its effect in T-ALL, disrupting Notch dimerization did not have a marked influence on the ability of Notch to direct hematopoietic progenitors to the T-cell fate. One of the dimerization-sensitive Notch targets that we identified, Hes1, is important for T-cell specification. Studies of Hes1 knockout mice showed that Hes1 is important in the expansion of very early T-cell progenitors (Tomita et al. 1999), but has little influence on later stages of differentiation (Kaneta et al. 2000). In our OP9-based assays, the ability of Notch 1 to drive formation of dimeric complexes did not influence T-cell specification or later development up to the DN2/DN3 stage. Unlike $p T \alpha$ and $c-M y c$, the R1985A mutation only partially abrogated Hes 1 expression, suggesting that it may have exceeded the minimal threshold required for early T-cell development. Alternatively, Hes1 expression is also influenced by other transcription factors, such as E2A and JunB, which may have compensated for defective formation of Notch dimers (Ikawa et al. 2006; Santaguida et al. 2009).

Our data suggest that the failure of R1985A to induce T-ALL is likely related to defects that preclude successful $\beta$ selection. R1985A-transduced DN3 cells were markedly deficient in $\beta$ selection, as evidenced by decreased DP differentiation and decreased proliferation. Successful $\beta$ selection and Notch-induced T-ALL both require Notch and pre-TCR signals (Allman et al. 2001; Bellavia et al. 2002; Ciofani et al. 2004), and $c-M y c$ and $p T \alpha$ are two dimerization-dependent Notch targets that exert important functions during $\beta$ selection and the induction and maintenance of T-ALL.

Signaling through the pre-TCR is important for the survival of thymocytes that have successfully rearranged their TCR $\beta$ chain, and for their subsequent proliferation and differentiation (von Boehmer and Fehling 1997; Aifantis et al. 2006). pT $\alpha$ is a direct Notch target, and CSL-binding sites have been identified in the $p T \alpha$ enhancer and promoter (Reizis and Leder 2002; Bellavia et al. 2007). Reporter gene assays suggest that the CSLbinding sites in the enhancer are particularly important for optimal pT $\alpha$ expression (Reizis and Leder 1999, 2002).
We now show that the CSL-binding sites in the $p T \alpha$ enhancer in both humans and mice are comprised of divergent SPS sites that respond to dimeric Notch transcriptional activation complexes. The paired sites consist of one previously identified CSL site that closely matches the CSL consensus and less conserved sequences $16 \mathrm{bp}$ away that nevertheless provide a second binding site for CSL/ICN1/MAML1 complexes, based on EMSA studies that show cooperative loading onto both the human and mouse $p T \alpha$ paired sites. The sequences of this second site diverge substantially from the CSL consensus sequence, especially in the human $p T \alpha$ promoter. The affinity for the second site is sufficiently weak that it appears to load complexes only when the first site is occupied. In contrast, both of the paired sites in the Hes1 promoter are able to bind CSL independently, with the weaker of the two sites showing an affinity twofold lower than that of the stronger (Nam et al. 2007; Gordon et al. 2008; Friedmann and Kovall 2010). Thus, the second CSLbinding site within paired sites can diverge substantially from the single-site CSL consensus motif, as also observed in the Hes5 locus (Arnett et al. 2010). As a result, the second site consensus sequence will likely need to be defined experimentally, since divergence in the sequences of these second CSL-binding sites may make it difficult or impossible to predict paired sites using bioinformatic approaches alone.

Notch exerts important functions during $\beta$ selection that are independent of pre-TCR signaling, as TCR transgenes fail to rescue loss of Notch signaling in DN3 cells (Ciofani and Zuniga-Pflucker 2005; Maillard et al. 2006). Our data suggest that Notch-dependent $c-M y c$ transcription in DN3 cells provides important proliferative and differentiation signals. In addition to its functions downstream from Notch, c-Myc is likely to have important functions downstream from pre-TCR signaling (Douglas et al. 2001; Dose et al. 2006). Gounari and colleagues (Dose et al. 2006) showed that pre-TCR signals enhance c-Myc levels, and that c-Myc is important for proliferation of post $\beta$ selection thymocytes as they develop into DP T cells. Although our data show that the Notch1:c-Myc axis is important for $\beta$ selection and T-ALL, it is possible that Notch regulation of $c-M y c$ involves both direct and indirect effects.

We used two different sets of mutations to identify and validate $c-M y c$ and $p T \alpha$ as dimerization-dependent Notch1 transcriptional targets. Most importantly, coexpression of the individual K1946E and E1950K mutants in trans restored expression of these genes to wild-type ICN1 levels. Thus, intermolecular Notch1 interactions are required for $c-M y c$ and $p T \alpha$ expression. These genetic data, together with the recently solved high-resolution crystal structure of a dimeric Notch transcription complex on DNA (Arnett et al. 2010), provide strong support for the importance of dimeric complexes in Notch-dependent transcriptional activation of certain target genes. Although we identified the functional paired sites in $p T \alpha$, the precise sites for Notch dimerization on $c-M y c$ remain to be determined; paired CSL-binding sites are not readily identifiable immediately upstream of the $c-M y c$ promoter, and 
the elements that control $c-M y c$ transcription are poorly understood (Harismendy and Frazer 2009). Long-range interactions between a putative $5^{\prime} c-M y c$ enhancer and the $c-M y c$ promoter have been described in colorectal cancer (Pomerantz et al. 2009), and similar long-range interactions between an enhancer containing a paired-site element and the promoter in $c-M y c$ may exist in T cells. While the details of Notch regulation of $c-M y c$ remain to be determined, our studies establish that Notch dimerization is essential for proper $c-M y c$ regulation.

In summary, our data provide new insights into possible mechanisms used by Notch to activate gene transcription and induce different outcomes. Dimerizationdependent transcriptional targets can be regulated by access of CSL/ICN/MAML complexes to either of the two CSL-binding sites, and the kinetics of assembly and turnover of the dimeric complex may be different from monomeric complexes. In both $\beta$ selection and Notchinduced T-ALL, it is possible that Notch dimerization results in coregulation of multiple Notch targets to coordinately achieve and/or maintain a high level of signaling tone. As dimerization is critical for the growth of T-ALL cells and possibly other Notch-related diseases, it may be possible to disrupt dimerization with selective inhibitors, which could have more favorable toxicity profiles than pan-Notch inhibitors, such as GSIs.

\section{Materials and methods}

\section{Reagents and plasmids}

JC-18 is an isomer of compound X (Searfoss et al. 2003) that was synthesized as described (Wu et al. 1998). The retroviral constructs MigR1-ICN1 and MigR1-DNMAML1(13-74)-GFP are described (Weng et al. 2003). The R1985A mutation was introduced using the QuikChange Site-Directed Mutagenesis kit (Stratagene). Primers for mutagenesis are R1985A forward (5'-CAGATCCTGATCCGGAACGCAGCCACAGACCTGGAT GC-3') and R1985A reverse (5'-GCATCCAGGTCTGTGGCTGC GTTCCGGATCAGGATCTG-3') MigR1-c-Myc was a kind gift from Bill Sha (University of California at Berkeley). For the experiments in which ICN1 was cotransduced with MigR1c-Myc, ICN1 was expressed from an MSCV-based retroviral vector that coexpresses the truncated nerve growth factor receptor (tNGFR) as a surrogate marker (Izon et al. 2001) and was detected by $\mathrm{PE}$ anti-NGFR (BD-Pharmingen); thus, it could be distinguished from GFP fluorescence. NGFR-ICN1 and NGFR-R1985A were obtained by subcloning ICN1 or R1985A from MigR1 into the MSCV tNGFR vector. All constructs were sequenced and tested for expression.

\section{$q R T-P C R$}

Total RNA was prepared using TRIzol (Invitrogen). Randomprimed total RNAs $(1 \mu \mathrm{g}$ from cell lines and $0.1 \mu \mathrm{g}$ from primary cells) were reverse-transcribed with SuperScript II (Invitrogen) according to the manufacturer's instructions. All PCR reactions were performed in triplicate. Primer sequences for real-time PCR were as follows: $p T \alpha$ forward, 5'-CAGGCTCTACCATCAGG CAT-3'; $p T \alpha$ reverse, 3'-ACCAGACAGGGTTGTCAAGG-5'; Hey1 forward, 5'-GGTACCCAGTGCCTTTGAGA-3'; Hey1 reverse, 5'-ACCTTTCCCTCCTGCAGTGT-3'; 18s rRNA forward, 5'-GCGCCGCTAGAGGTGAAAT-3'; 18s $r R N A$ reverse,
5'-GGCGGGTCATGGGAATAAC-3' . Primers were used at a final concentration of $0.4 \mu \mathrm{M}$. Real-time amplification in TaqMan universal PCR Master Mix (Applied Biosystems) was performed with initial denaturation for $3 \mathrm{~min}$ at $95^{\circ} \mathrm{C}$ followed by 40 cycles of two-step amplification $\left(15 \mathrm{sec}\right.$ at $95^{\circ} \mathrm{C}, 1 \mathrm{~min}$ at $\left.65^{\circ} \mathrm{C}\right)$, and was analyzed on the ABI Prism 7900 (Applied Biosystems). c-Myc, CD25, and Hes1 TaqMan primers were purchased from Applied Biosystems.

\section{EMSA}

EMSA was performed as described (Nam et al. 2007). Residues 1761-2127 of human Notch1 were inserted into a modified pGEX4T1 vector to express RAMANK-1 (RA-1). Expression and purification of various polypeptides were as described (Nam et al. 2003, 2006). The final concentration in each EMSA (total volume, 14 $\mu \mathrm{L}$ ) was $0.03 \mu \mathrm{M}$ DNA, $0.15 \mu \mathrm{M}$ CSL, $0.9 \mu \mathrm{M}$ ICN1, and $1.9 \mu \mathrm{M}$ MAML1.

\section{Luciferase reporter gene assays}

Empty pcDNA3 or pcDNA3 expressing ICN1 (or indicated mutants) was transiently cotransfected in triplicate into human 293 cells with firefly luciferase reporter genes driven by elements from the Hes 1 promoter or the human $p T \alpha$ enhancer as described (Reizis and Leder 2002). Cells were transfected using Fugene 6 reagent (Roche Molecular Biochemicals) with $0.8 \mu \mathrm{g}$ of firefly luciferase reporter constructs, $0.1 \mu \mathrm{g}$ of expression vectors, and $0.1 \mu \mathrm{g}$ of Renilla luciferase expression vector. Luciferase activities were measured $24 \mathrm{~h}$ later using the Promega Dual Luciferase kit. Firefly luciferase activities were normalized with Renilla luciferase control values and expressed relative to the empty vector lysate, which was set arbitrarily to a value of 1 .

\section{Purification of MPP and DN3 cells}

BM cells and thymocytes were treated with ACK lysis buffer (Cambrex) to remove red blood cells and were prepared as a single-cell suspension. Total MPPs were identified as $\mathrm{Lin}^{-} \mathrm{Sca} 1^{+} \mathrm{C}-\mathrm{Kit}^{+} \mathrm{Flt} 3^{+} \mathrm{BM}$ cells; this population contains Flt $3^{\text {lo }}$ cells as well as Flt $3^{\text {hi }}$ lymphoid-primed MPPs. DN3 cells were defined as $\mathrm{Lin}^{-} \mathrm{c}-\mathrm{Kit}^{-} \mathrm{CD} 25^{+}$cells from $\alpha$-CD4- and $\alpha$-CD8-depleted thymocytes. Cells were sorted accordingly on the FACSAria (BD Biosciences) and analyzed on the LSR-II (BD Biosciences). The lineage mixture included $\alpha$-B220 (RA3-6B2), $\alpha$-CD19 (1D3), $\alpha$-CD11b (M1/70), $\alpha$-Gr1 (8C5), $\alpha$-CD11c (N418), $\alpha$-NK1.1 (PK136), $\alpha$-Ter119 (TER-119), $\alpha$-CD3 $\varepsilon$ (17A2), $\alpha$-CD8 $\alpha$ (53-6.7), $\alpha$-CD8 $\beta$ (H35-17.2), anti-TCR $\beta$ (H57-597), and anti-TCR $\gamma \delta$ (GL-3) (eBioscience).

\section{Retroviral transduction}

Production of high-titer retroviruses was performed as described (Chiang et al. 2008). Retroviral transduction of T-ALL cell lines was carried out as described (Weng et al. 2006). Briefly, $2 \times 10^{6}$ cells were added with the appropriate amount of viral supernatant and $4 \mu \mathrm{g} / \mathrm{mL}$ polybrene (Sigma) in a final volume of $2 \mathrm{~mL}$. The mixture was then centrifuged at $2500 \mathrm{rpm}$ for $60 \mathrm{~min}$. Transduction efficiency was measured $48 \mathrm{~h}$ post-transduction by flow cytometry.

For retroviral transduction of MPPs and DN3 cells, six-well or 12-well plates were coated with $20 \mu \mathrm{g} / \mathrm{mL}$ RetroNectin (Takara) according to the manufacturer's instructions. Normalized retroviral supernatants (Chiang et al. 2008) were added into wells and incubated for $4-6 \mathrm{~h}$ at $37^{\circ} \mathrm{C}$ before washing with PBS. Purified MPPs or DN3 cells were resuspended in the stimulation 
cocktails DMEM, penicillin-streptomycin, 15\% FCS, L-glutamate (2 mM), IL-3 (10 ng/mL), IL-6 (10 ng/mL), SCF $(20 \mathrm{ng} / \mathrm{mL})$, and Flt3-ligand $(20 \mathrm{ng} / \mathrm{mL})$ for MPP; and RPMI, penicillin-streptomycin, $15 \%$ FCS, IL-7 $(20 \mathrm{ng} / \mathrm{mL})$, SCF $(20 \mathrm{ng} / \mathrm{mL})$, and Flt3ligand $(20 \mathrm{ng} / \mathrm{mL})$ for $\mathrm{DN} 3$; and then added to virus-bound RetroNectin-coated plates. Transduced DN3 cells were sorted within $16 \mathrm{~h}$. Transduced MPPs were sorted $36 \mathrm{~h}$ post-infection.

\section{$B M T$}

Retroviral transduction of BM cells and transplant into lethally irradiated recipients were carried out as described using normalized retroviral supernatants (Chiang et al. 2008). In brief, BM cells from 4- to 8-wk-old C57Bl/6 mice (Taconic) were harvested $4 \mathrm{~d}$ after intravenous administration of 5 -FU $(250 \mathrm{mg} / \mathrm{kg})$. The cells were cultured overnight in the presence of IL-3 $(6 \mathrm{ng} / \mathrm{mL})$, IL-6 (5-10 ng/mL), and SCF (100 ng/mL). Two rounds of retroviral transduction were performed once per day on the following $2 \mathrm{~d}$. Cells $\left(5 \times 10^{5}\right)$ were injected intravenously into lethally irradiated (900 rads) recipients. Mice were supplied with drinking water with antibiotics for 2 wk post-BMT. Experiments were performed according to guidelines from the National Institutes of Health and with an approved protocol from the University of Pennsylvania Animal Care and Use Committee.

\section{Flow cytometry}

Cells were stained with the indicated antibodies in FACS buffer ( $1 \times$ DPBS, $10 \mathrm{mM}$ HEPES, $0.02 \% \mathrm{NaN} 3,0.2 \%$ BSA [w/v] ) on ice in the presence of rat and mouse IgG (Sigma-Aldrich) for $20 \mathrm{~min}$, then washed and resuspended in FACS buffer. Acquisition was performed on a FACSCalibur or LSR II (Beckton Dickinson). Dead cells and doublets were excluded based on FSC-W and SSCW characteristics and DAPI staining. Data were analyzed with FlowJo software (Tree Star).

\section{CFSE assay}

MPPs and DN3 were sorted from wild-type B6 mice and transduced with indicated tNGFR virus as described above. NGFR ${ }^{+}$ MPPs were sorted $32 \mathrm{~h}$ post-transduction, whereas $\mathrm{NGFR}^{+} \mathrm{DN} 3$ were sorted $16 \mathrm{~h}$ after transduction. Sorted MPPs and DN3 were labeled with CFSE (Molecular Probes/Invitrogen) according to the instruction manual, before seeding onto OP9 stromal cells. Briefly, sorted NGFR ${ }^{+}$cells were resuspended in warm PBS $/ 0.1 \%$ $\mathrm{BSA}+5 \% \mathrm{FCS}$ at $1 \times 10^{6}$ per milliliter. Cells were then mixed with an equal volume of $20 \mu \mathrm{M}$ CSFE in PBS/0.1\% BSA $+5 \%$ FCS to achieve a final concentration of $10 \mu \mathrm{M}$ CFSE. Cells were incubated for $10 \mathrm{~min}$ at $37^{\circ} \mathrm{C}$. CFSE loading was stopped by adding 5 vol of $4{ }^{\circ} \mathrm{C} \mathrm{PBS} / 0.1 \%$ BSA $+5 \%$ FCS and was incubated on ice for $5 \mathrm{~min}$. Cells were then washed three times with warm $M E M \alpha$ medium before counting and were seeded onto OP9 stromal cells. CFSE-labeled tNGFR-transduced MPPs were harvested from OP9 culture on day 3, whereas CFSE-labeled tNGFR-transduced DN3s were harvested on day 5.

\section{Acknowledgments}

We are grateful to B. Reizis for providing reagents, C. Romany and K. Toscano for retroviral production, and members of the Pear laboratory, T. Kadesch, and G. Qing for advice and comments on the manuscript. We thank William Demuth for cell sorting. This work was supported by grants from the National Institute of Health to Y.L. (R01AG02666), A.B. (RC1HL099758), S.C.B. (P01CA119070), J.C.A. (P01CA119070), and W.S.P. (R01AI047833, P01CA119070), and a Leukemia and Lymphoma
Society SCOR Award to J.C.A., S.C.B., and W.S.P. Individual support was provided by an NIH-funded Institutional Research Training Grant (T32-DK07780) and a Fellow Award from the Lymphoma Research Foundation to H.L., an NIH-funded Institutional Research Training Grant (T32-CA009140) to A.W.S.C., a career development award from the NCI (K08 CA120544-01) to M.Y.C., a Fellow Award from the American Cancer Society to K.L.A., and a Fellow Award from the Leukemia and Lymphoma Society to H.W.

\section{References}

Aifantis I, Mandal M, Sawai K, Ferrando A, Vilimas T. 2006. Regulation of T-cell progenitor survival and cell-cycle entry by the pre-T-cell receptor. Immunol Rev 209: 159-169.

Allman D, Karnell FG, Punt JA, Bakkour S, Xu L, Myung PS, Koretzky GA, Pui JC, Aster JC, Pear WS. 2001. Separation of Notch1 promoted lineage commitment and expansion/ transformation in developing T cells. I Exp Med 194: 99106.

Arnett KL, Hass M, McArthur DG, Aster JC, Kopan R, Blacklow SC. 2010. Structural and mechanistic insights into cooperative assembly of dimeric Notch transcription complexes. Nat Struct Mol Biol (in press).

Artavanis-Tsakonas S, Rand MD, Lake RJ. 1999. Notch signaling: Cell fate control and signal integration in development. Science 284: 770-776.

Aster JC, Xu L, Karnell FG, Patriub V, Pui JC, Pear WS. 2000. Essential roles for ankyrin repeat and transactivation domains in induction of T-cell leukemia by Notch1. Mol Cell Biol 20: 7505-7515.

Aster JC, Pear WS, Blacklow SC. 2008. Notch signaling in leukemia. Annu Rev Pathol 3: 587-613.

Bailey AM, Posakony JW. 1995. Suppressor of hairless directly activates transcription of enhancer of split complex genes in response to Notch receptor activity. Genes Dev 9: 26092622.

Bellavia D, Campese AF, Checquolo S, Balestri A, Biondi A, Cazzaniga G, Lendahl U, Fehling HJ, Hayday AC, Frati L, et al. 2002. Combined expression of $\mathrm{pT} \alpha$ and Notch 3 in T cell leukemia identifies the requirement of preTCR for leukemogenesis. Proc Natl Acad Sci 99: 3788-3793.

Bellavia D, Mecarozzi M, Campese AF, Grazioli P, Talora C, Frati L, Gulino A, Screpanti I. 2007. Notch3 and the Notch3upregulated RNA-binding protein $\mathrm{HuD}$ regulate Ikaros alternative splicing. EMBO I 26: 1670-1680.

Bhandoola A, von Boehmer H, Petrie HT, Zuniga-Pflucker JC. 2007. Commitment and developmental potential of extrathymic and intrathymic $\mathrm{T}$ cell precursors: Plenty to choose from. Immunity 26: 678-689.

Bray SJ. 2006. Notch signalling: A simple pathway becomes complex. Nat Rev Mol Cell Biol 7: 678-689.

Cave JW, Loh F, Surpris JW, Xia L, Caudy MA. 2005. A DNA transcription code for cell-specific gene activation by notch signaling. Curr Biol 15: 94-104.

Chiang MY, Xu L, Shestova O, Histen G, L'Heureux S, Romany C, Childs ME, Gimotty PA, Aster JC, Pear WS. 2008. Leukemia-associated NOTCH1 alleles are weak tumor initiators but accelerate K-ras-initiated leukemia. J Clin Invest 118: 3181-3194.

Ciofani M, Zuniga-Pflucker JC. 2005. Notch promotes survival of pre- $T$ cells at the $\beta$-selection checkpoint by regulating cellular metabolism. Nat Immunol 6: 881-888.

Ciofani M, Schmitt TM, Ciofani A, Michie AM, Cuburu N, Aublin A, Maryanski JL, Zuniga-Pflucker JC. 2004. Obligatory role for cooperative signaling by pre-TCR and Notch 
during thymocyte differentiation. I Immunol 172: 52305239.

Deftos ML, Huang E, Ojala EW, Forbush KA, Bevan MJ. 2000. Notch1 signaling promotes the maturation of CD4 and CD8 SP thymocytes. Immunity 13: 73-84.

De Smedt M, Reynvoet K, Kerre T, Taghon T, Verhasselt B, Vandekerckhove B, Leclercq G, Plum J. 2002. Active form of Notch imposes $\mathrm{T}$ cell fate in human progenitor cells. I Immunol 169: 3021-3029.

Dose M, Khan I, Guo Z, Kovalovsky D, Krueger A, von Boehmer H, Khazaie K, Gounari F. 2006. c-Myc mediates pre-TCRinduced proliferation but not developmental progression. Blood 108: 2669-2677.

Douglas NC, Jacobs H, Bothwell AL, Hayday AC. 2001. Defining the specific physiological requirements for c-Myc in $\mathrm{T}$ cell development. Nat Immunol 2: 307-315.

Felsher DW, Bishop JM. 1999. Reversible tumorigenesis by MYC in hematopoietic lineages. Mol Cell 4: 199-207.

Friedmann DR, Kovall RA. 2010. Thermodynamic and structural insights into CSL-DNA complexes. Protein Sci 19: 3446.

Gonzalez-Garcia S, Garcia-Peydro M, Martin-Gayo E, Ballestar E, Esteller M, Bornstein R, de la Pompa JL, Ferrando AA, Toribio ML. 2009. CSL-MAML-dependent Notch1 signaling controls $\mathrm{T}$ lineage-specific IL-7R $\alpha$ gene expression in early human thymopoiesis and leukemia. J Exp Med 206: 779-791.

Gordon WR, Arnett KL, Blacklow SC. 2008. The molecular logic of Notch signaling-A structural and biochemical perspective. J Cell Sci 121: 3109-3119.

Harismendy O, Frazer KA. 2009. Elucidating the role of 8q24 in colorectal cancer. Nat Genet 41: 868-869.

Hozumi K, Abe N, Chiba S, Hirai H, Habu S. 2003. Active form of Notch members can enforce $\mathrm{T}$ lymphopoiesis on lymphoid progenitors in the monolayer culture specific for B cell development. I Immunol 170: 4973-4979.

Hozumi K, Mailhos C, Negishi N, Hirano K, Yahata T, Ando K, Zuklys S, Hollander GA, Shima DT, Habu S. 2008. Delta-like 4 is indispensable in thymic environment specific for $\mathrm{T}$ cell development. J Exp Med 205: 2507-2513.

Ikawa T, Kawamoto H, Goldrath AW, Murre C. 2006. E proteins and Notch signaling cooperate to promote $\mathrm{T}$ cell lineage specification and commitment. J Exp Med 203: 1329-1342.

Izon DJ, Punt JA, Xu L, Karnell FG, Allman D, Myung PS, Boerth NJ, Pui JC, Koretzky GA, Pear WS. 2001. Notch1 regulates maturation of $\mathrm{CD}^{+}$and $\mathrm{CD} 8^{+}$thymocytes by modulating TCR signal strength. Immunity 14: 253-264.

Kaneta M, Osawa M, Sudo K, Nakauchi H, Farr AG, Takahama Y. 2000. A role for pref-1 and HES-1 in thymocyte development. I Immunol 164: 256-264.

Koch U, Fiorini E, Benedito R, Besseyrias V, Schuster-Gossler K, Pierres M, Manley NR, Duarte A, Macdonald HR, Radtke F. 2008. Delta-like 4 is the essential, nonredundant ligand for Notch1 during thymic T cell lineage commitment. I Exp Med 205: 2515-2523.

Kopan R, Ilagan MX. 2009. The canonical Notch signaling pathway: Unfolding the activation mechanism. Cell 137: 216-233.

Li X, Gounari F, Protopopov A, Khazaie K, von Boehmer H. 2008. Oncogenesis of T-ALL and nonmalignant consequences of overexpressing intracellular NOTCH1. I Exp Med 205: 2851-2861.

Maillard I, Tu L, Sambandam A, Yashiro-Ohtani Y, Millholland J, Keeshan K, Shestova O, Xu L, Bhandoola A, Pear WS. 2006. The requirement for Notch signaling at the $\beta$-selection checkpoint in vivo is absolute and independent of the preT cell receptor. I Exp Med 203: 2239-2245.
Michie AM, Zuniga-Pflucker JC. 2002. Regulation of thymocyte differentiation: Pre-TCR signals and $\beta$-selection. Semin Immunol 14: 311-323.

Nam Y, Weng AP, Aster JC, Blacklow SC. 2003. Structural requirements for assembly of the CSL.intracellular Notch1. Mastermind-like 1 transcriptional activation complex. I Biol Chem 278: 21232-21239.

Nam Y, Sliz P, Song L, Aster JC, Blacklow SC. 2006. Structural basis for cooperativity in recruitment of MAML coactivators to Notch transcription complexes. Cell 124: 973-983.

Nam Y, Sliz P, Pear WS, Aster JC, Blacklow SC. 2007. Cooperative assembly of higher-order Notch complexes functions as a switch to induce transcription. Proc Natl Acad Sci 104: 2103-2108.

Ong CT, Cheng HT, Chang LW, Ohtsuka T, Kageyama R, Stormo GD, Kopan R. 2006. Target selectivity of vertebrate notch proteins. Collaboration between discrete domains and CSL-binding site architecture determines activation probability. J Biol Chem 281: 5106-5119.

Palomero T, Lim WK, Odom DT, Sulis ML, Real PJ, Margolin A, Barnes KC, O'Neil J, Neuberg D, Weng AP, et al. 2006. $\mathrm{NOTCH} 1$ directly regulates c-MYC and activates a feedforward-loop transcriptional network promoting leukemic cell growth. Proc Natl Acad Sci 103: 18261-18266.

Pear WS, Aster JC, Scott ML, Hasserjian RP, Soffer B, Sklar J, Baltimore D. 1996. Exclusive development of T cell neoplasms in mice transplanted with bone marrow expressing activated Notch alleles. J Exp Med 183: 2283-2291.

Pear WS, Miller JP, Xu L, Pui JC, Soffer B, Quackenbush RC, Pendergast AM, Bronson R, Aster JC, Scott ML, et al. 1998. Efficient and rapid induction of a chronic myelogenous leukemia-like myeloproliferative disease in mice receiving P210 bcr/abl-transduced bone marrow. Blood 92: 3780-3792.

Pomerantz MM, Ahmadiyeh N, Jia L, Herman P, Verzi MP, Doddapaneni H, Beckwith CA, Chan JA, Hills A, Davis M, et al. 2009. The 8q24 cancer risk variant rs6983267 shows long-range interaction with MYC in colorectal cancer. Nat Genet 41: 882-884.

Pui JC, Allman D, Xu L, DeRocco S, Karnell FG, Bakkour S, Lee JY, Kadesch T, Hardy RR, Aster JC, et al. 1999. Notch1 expression in early lymphopoiesis influences $\mathrm{B}$ versus $\mathrm{T}$ lineage determination. Immunity 11: 299-308.

Radtke F, Wilson A, Stark G, Bauer M, van Meerwijk J, MacDonald HR, Aguet M. 1999. Deficient T cell fate specification in mice with an induced inactivation of Notch1. Immunity 10: 547-558.

Radtke F, Fasnacht N, Macdonald HR. 2010. Notch signaling in the immune system. Immunity 32: 14-27.

Reizis B, Leder P. 1999. Expression of the mouse pre-T cell receptor $\alpha$ gene is controlled by an upstream region containing a transcriptional enhancer. I Exp Med 189: 1669-1678.

Reizis B, Leder P. 2002. Direct induction of T lymphocytespecific gene expression by the mammalian Notch signaling pathway. Genes Dev 16: 295-300.

Sambandam A, Maillard I, Zediak VP, Xu L, Gerstein RM, Aster JC, Pear WS, Bhandoola A. 2005. Notch signaling controls the generation and differentiation of early $\mathrm{T}$ lineage progenitors. Nat Immunol 6: 663-670.

Santaguida M, Schepers K, King B, Sabnis AJ, Forsberg EC, Attema JL, Braun BS, Passegue E. 2009. JunB protects against myeloid malignancies by limiting hematopoietic stem cell proliferation and differentiation without affecting selfrenewal. Cancer Cell 15: 341-352.

Schmitt TM, Zuniga-Pflucker JC. 2002. Induction of T cell development from hematopoietic progenitor cells by deltalike-1 in vitro. Immunity 17: 749-756. 
Searfoss GH, Jordan WH, Calligaro DO, Galbreath EJ, Schirtzinger LM, Berridge BR, Gao H, Higgins MA, May PC, Ryan TP. 2003. Adipsin, a biomarker of gastrointestinal toxicity mediated by a functional $\gamma$-secretase inhibitor. I Biol Chem 278: 4610746116.

Sharma VM, Calvo JA, Draheim KM, Cunningham LA, Hermance N, Beverly L, Krishnamoorthy V, Bhasin M, Capobianco AJ, Kelliher MA. 2006. Notch1 contributes to mouse T-cell leukemia by directly inducing the expression of c-myc. Mol Cell Biol 26: 8022-8031.

Taghon T, Yui MA, Pant R, Diamond RA, Rothenberg EV. 2006. Developmental and molecular characterization of emerging $\beta$ - and $\gamma \delta$-selected pre-T cells in the adult mouse thymus. Immunity 24: 53-64.

Tan JB, Visan I, Yuan JS, Guidos CJ. 2005. Requirement for Notch1 signals at sequential early stages of intrathymic $\mathrm{T}$ cell development. Nat Immunol 6: 671-679.

Tanigaki K, Tsuji M, Yamamoto N, Han H, Tsukada J, Inoue H, Kubo M, Honjo T. 2004. Regulation of $\alpha \beta / \gamma \delta$ T cell lineage commitment and peripheral T cell responses by Notch/RBP-J signaling. Immunity 20: 611-622.

Tomita K, Hattori M, Nakamura E, Nakanishi S, Minato N, Kageyama R. 1999. The bHLH gene Hesl is essential for expansion of early T cell precursors. Genes Dev 13: 12031210.

von Boehmer H, Fehling HJ. 1997. Structure and function of the pre-T cell receptor. Annu Rev Immunol 15: 433-452.

Weng AP, Nam Y, Wolfe MS, Pear WS, Griffin JD, Blacklow SC, Aster JC. 2003. Growth suppression of pre-T acute lymphoblastic leukemia cells by inhibition of notch signaling. Mol Cell Biol 23: 655-664.

Weng AP, Millholland JM, Yashiro-Ohtani Y, Arcangeli ML, Lau A, Wai C, Del Bianco C, Rodriguez CG, Sai H, Tobias J, et al. 2006. c-Myc is an important direct target of Notch1 in T-cell acute lymphoblastic leukemia/lymphoma. Genes Dev 20: 2096-2109.

Wilson JJ, Kovall RA. 2006. Crystal structure of the CSL-NotchMastermind ternary complex bound to DNA. Cell 124: 985996.

Wilson A, MacDonald HR, Radtke F. 2001. Notch 1-deficient common lymphoid precursors adopt a B cell fate in the thymus. J Exp Med 194: 1003-1012.

Wolfer A, Wilson A, Nemir M, MacDonald HR, Radtke F. 2002. Inactivation of Notch 1 impairs VDJ $\beta$ rearrangement and allows pre-TCR-independent survival of early $\alpha \beta$ lineage thymocytes. Immunity 16: 869-879.

Wu J, Tung JS, Thorsett ED, Pleiss MA, Nissen JS, Neitz J, Latimer LH, Varghese J, Freedman S, Britton TC, et al. 1998. Preparation of cycloalkyl, lactam, lactone and related compounds for inhibiting $\beta$-amyloid peptide release and/or its synthesis. PCT Int Appl WO 98/28268.

Yashiro-Ohtani Y, He Y, Ohtani T, Jones ME, Shestova O, Xu L, Fang TC, Chiang MY, Intlekofer AM, Blacklow SC, et al. 2009. Pre-TCR signaling inactivates Notch1 transcription by antagonizing E2A. Genes Dev 23: 1665-1676. 


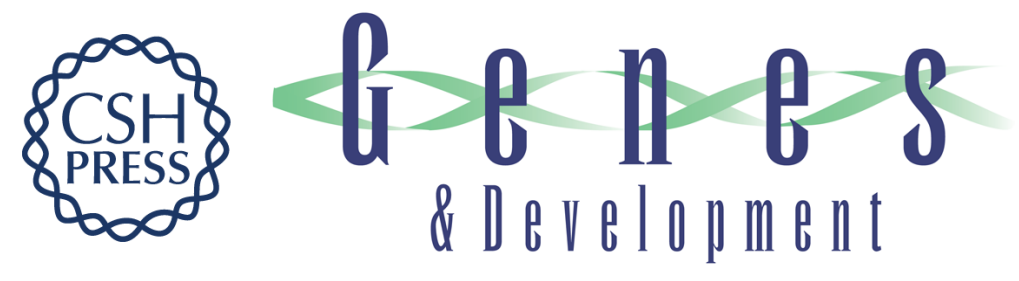

\section{Notch dimerization is required for leukemogenesis and T-cell development}

Hudan Liu, Anthony W.S. Chi, Kelly L. Arnett, et al.

Genes Dev. 2010, 24: originally published online October 8, 2010

Access the most recent version at doi:10.1101/gad.1975210

\section{Supplemental http://genesdev.cshlp.org/content/suppl/2010/10/01/gad.1975210.DC1 Material}

References This article cites 62 articles, 32 of which can be accessed free at: http://genesdev.cshlp.org/content/24/21/2395.full.html\#ref-list-1

\section{License}

Email Alerting

Receive free email alerts when new articles cite this article - sign up in the box at the top Service 